\title{
The Hilar Height Ratio in Normal Chest Radiographs of Adults Seen at Selected Tertiary Hospitals in Kampala, Uganda; A Forgotten Parameter in Pulmonary Medicine
}

Daniel Muhati Wendo ( $\square$ danwendo@gmail.com )

Makerere University College of Health Sciences

Samuel Bugeza

Makerere University College of Health Sciences

Sam Nseko

Makerere University College of Health Sciences

Senai Goitom Sereke

Makerere University College of Health Sciences

Faith Ameda

Makerere University College of Health Sciences

\section{Research Article}

Keywords: hilar height, ratio, normal chest radiograph, adults

Posted Date: October 7th, 2021

DOI: https://doi.org/10.21203/rs.3.rs-955671/v1

License: (c) (i) This work is licensed under a Creative Commons Attribution 4.0 International License.

Read Full License 


\section{Abstract}

Background: The hilar height ratio (HHR) is a numerical expression of the hila position. Displacement of the pulmonary hilum is the most reliable indirect sign, in conditions that result in pulmonary volume changes. Despite the high utility of the chest radiograph, it has a relatively low diagnostic accuracy, high interobserver disagreement and numerous errors following interpretation. Routine use of the HHR with knowledge of the normal ranges would, therefore, help improve the overall chest radiograph sensitivity, reduce on errors and the interobserver disagreement in the interpretation of pulmonary volume changes. This study aims to determine the HHR in our study population, compare it with previous studies, and to relate it with sex, stratified age groups, height and body mass index (BMI).

Methods: A consecutive cross-sectional study with purposive sampling were used to filter out a total of 384 normal chest radiographs of adults seen from three tertiary hospitals in Kampala, Uganda. The right and left HHRs were evaluated for each chest radiograph, along with the age, sex weight, height and BMI.

Results: The median right HHR for the participants was 1.42 (IQR = 1.31- 1.57), and the median left HHR was $0.92(I Q R=0.86-0.98)$. There was a significant mean difference in the right HHR between the sex groups $(p=0.017)$ and age groups $(p=0.001)$. The mean difference in the left HHR was not affected by sex $(p=0.178)$ or age $(p=0.198)$. The right and left HHRs showed a very weak correlation to height $(r=-$ 0.10 and $r=0.08$, respectively). The right and left HHRs were not significantly different among the BMI groups ( $p=0.254$ and 0.20 respectively).

Conclusion: The median left HHR was not affected by sex, age, weight and height while the right HHR varied with sex and age in our study population. Weight and height do not affect HHRs. The females in our study population had a higher positioned right hilum, whereas the position of the right hilum progressively lowered with increasing age.

\section{Background}

In Uganda, chest radiography utility remains high despite the increasing availability of chest computed tomography and accounts for 30 to $40 \%$ of all x-ray examinations done at all levels of health-care delivery (1). Despite this, the diagnostic accuracy of chest radiography is relatively low with an overall sensitivity of $49 \%(95 \% \mathrm{Cl}, 40-58 \%)$ and specificity of $92 \%$ (86-95\%) (2). In addition, interobserver disagreement in radiograph interpretation ranges from $0.3 \%$ to $58 \%(3,4)$ with an estimated interpretation error of up to $49 \%$ (5). The chest radiograph also contains hidden areas that pose challenges in their evaluation due to the presence of overlying structures such as the lung apices, retrocardiac and inferior lung bases (6). These hidden areas contribute to the most commonly missed findings and result in frequent false-negative or false-positive interpretations (7).

Displacement of the pulmonary hilum is the most reliable indirect sign found in many chest pathologies that result in alterations of pulmonary volume (8) as was originally described by Robbins and Hale (9) and later by Lubert and Krause (10). The hilar height ratio (HHR) is a numerical expression of the hila 
position (11) that helps to provide a standardised way to quantify pulmonary volume changes. It allows recognition of a hilar positional abnormality without the necessity for comparison of both sides (12). When an abnormal HHR is present in the absence of pulmonary disease, then infrapulmonary and subphrenic disease should be suspected. An abnormal HHR is not always an absolute sign of disease, but it should cause the radiologist to scrutinise the radiograph carefully for underlying pathology (12).

The routine use of the HHR with knowledge of the normal ranges would, therefore, help improve the overall chest radiograph sensitivity, reduce on errors and the interobserver disagreement in the interpretation of pulmonary volume changes $(3,8)$. There was however limited use and awareness of the HHR due to the fact that there are no established HHR values for the normal radiographs seen in Uganda and using values obtained from different demographics would affect the interpretation. This study sought to determine the HHR in our study population, to establish how it compared with previous studies, and to relate it with sex, stratified age groups, height and BMI.

\section{Methods}

\section{Study design and setting}

This was a consecutive cross-sectional study conducted at the radiology departments of St. Francis Hospital Nsambya, Kawempe National Referral Hospital and Case Hospital located in Kampala, Uganda from September 2019 to November 2019. St. Francis Hospital is located on Nsambya hill in Makindye Division, one of the five administrative divisions of the city. It lies approximately 5 kilometers southeast of the central business district of Kampala. It is a tertiary referral hospital with a capacity of 361 beds and approximately 450 chest $x$-rays are performed per month. Kawempe National Referral Hospital is a tertiary hospital, located approximately 7.1 kilometers, by road side, north of the city's central business district, along the Kampala-Gulu Highway. The radiology department offers an $\mathrm{x}$ ray service with an average of 30 chest $x$-rays per month. Case hospital is an urban, private, tertiary hospital in Kampala, Uganda. It is located at 67 - 71 Buganda Road, on Nakasero hill. Around 100 chest x-rays are performed per a month.

\section{Study population}

Normal chest radiographs (Posterior anterior view, erect) of asymptomatic adults who came for routine screening examination as interpreted by the principal investigator and confirmed by an independent radiologist were used in this study. Purposive sampling was used to filter out a total of 384 normal chest radiographs of adults collected consecutively from all three sites in proportions based on the average normal chest radiographs seen per facility over three months. An adult was taken to be a person 15 years of age and above to allow for comparison with previous studies previous studies done in Kenya (11), United states of America (USA) (12) and south Korea (13) which used the same cut-off. A normal chest radiograph was defined as one that fulfilled all the quality requirements and had clear lung fields with no pulmonary or extrapulmonary abnormalities as interpreted by the principal investigator and confirmed by 
an independent radiologist. All chest radiographs included in the study were of non-symptomatic adults undergoing routine medical screening.

\section{Sample size}

The ideal sample size for this study was estimated using the Kish Leslie formula given below:

$\mathrm{n}=(\mathrm{z})^{2} \mathrm{p}(1-\mathrm{p}) / \mathrm{d}^{2}$

Where;

$\mathrm{n}=$ sample size

$z=$ level of confidence according to the standard normal distribution (for a level of confidence of $95 \%, z=$ 1.96)

$p=$ estimated proportion of the population that presents the characteristic (when unknown we use $p=$ $0.5)$

$d=$ tolerated margin of error (for example we want to know the real proportion within $5 \%$ )

To calculate a proportion with a $95 \%$ level of confidence and a margin of error of $5 \%$ we obtain

$\mathrm{n}=(1.96) 2 / 4(0.05) 2=384$

\section{Study Procedure}

A semi structured data collection tool was used to collect bio-demographics and relevant history (Appendix 1). The principal investigator collected data with the help of two qualified radiographers trained as research assistants. The research assistants identified the adults sent for routine screening and ensured that the radiographs were well taken and digitally stored. Purposive sampling was used to filter out those with normal chest radiographs to be included in the study as interpreted by the principal investigator and confirmed by an independent radiologist.

The HHR was calculated by drawing a straight line parallel to the thoracic spine from the highest point of the pulmonary apex to the diaphragm and an intersecting line from the midpoint of the hilum perpendicular to the vertical line. The distance from the lung apex to the hilum was then divided by the distance from the hilum to the diaphragm as suggested by Homer (12) (Figure 1).

\section{Data analysis}

The HHR was evaluated on the right and left side for each chest radiograph, and this information was recorded along with the age, sex weight, height and BMI. The final results were analysed using STATA version 16. The socio-demographic and clinical characteristics were summarised using frequencies and percentages. The right and left hilar heights were normally distributed and hence summarised using 
mean and standard deviation whereas the right and left hilar height ratios were skewed and hence summarised using median and interquartile ranges.

The Wilcoxon rank sum test was used to test the mean difference in the left and right hilar height ratios between the sex groups. The Kruskal Wallis test was used to test the mean difference between the left and right hilar height ratios and the different age groups and BMI groups. The Spearman correlation coefficient was used to determine the linear relationship between right and left hilar height ratios and height of the participant.

\section{Results}

Of the 384 participants, majority $(85.7 \%, n=329)$ were males and aged 15 to $30(45.6 \%, n=175)$. The mean height of the participants was $1.66 \pm 0.106$ meters. Most $(83.9 \%, n=322)$ participants had normal BMI (Table 1).

Table 1

Socio-demographic and clinical characteristics of adults in three tertiary hospitals in Kampala.

\begin{tabular}{|llll|}
\hline Variable & Category & Frequency & $\%$ \\
\hline Site & Kawempe Hospital (1) & 68 & 17.7 \\
\hline & Case Hospital (2) & 100 & 26.0 \\
\hline Age & St. Francis Hospital (3) & 216 & 56.3 \\
\hline & 15- 30 years & 175 & 45.6 \\
\hline & 31-45 years & 156 & 40.6 \\
\hline Sex & 46-60 years & 49 & 12.8 \\
\hline & 61+ years & 4 & 1.0 \\
\hline BMI & Male & 329 & 85.7 \\
\hline & Female & 55 & 14.3 \\
\hline & Underweight & 5 & 1.3 \\
\hline Participants' height & Normal weight & 322 & 83.9 \\
\hline
\end{tabular}

The mean right hilar height A was $13.25 \pm 1.33 \mathrm{~cm}$, while for $B$ was $9.24 \pm 1.24 \mathrm{~cm}$. The mean left hilar height $C$ was $11.59 \pm 1.14 \mathrm{~cm}$, and for $D$ was $12.55 \pm 1.27 \mathrm{~cm}$. The median right hilar height ratio for the participants was 1.42 (IQR: 1.31- 1.57), and the median left hilar height ratio was 0.92 (IQR: 0.86- 0.98) (Table 2). 
Table 2

The hilar heights and hilar height ratios descriptive measures of adults at selected tertiary hospitals in Kampala

\begin{tabular}{|c|c|c|}
\hline Outcome variable & Shapiro-Wilks normality test* & Descriptive measures \\
\hline Right Hilar Height A & 0.829 & $($ Mean $=13.25 \mathrm{~cm})(\mathrm{SD}=1.33 \mathrm{~cm})$ \\
\hline Right Hilar Height B & 0.833 & $($ Mean $=9.24 \mathrm{~cm})(\mathrm{SD}=1.24 \mathrm{~cm})$ \\
\hline Right Hilar Height Ratio & $<0.001$ & $($ Median $=1.42)(\mathrm{IQR}=1.31-1.57)$ \\
\hline Left Hilar Height $\mathrm{C}$ & 0.859 & $($ Mean $=11.59 \mathrm{~cm})(\mathrm{SD}=1.14 \mathrm{~cm})$ \\
\hline Left Hilar Height D & 0.147 & $($ Mean $=12.55 \mathrm{~cm})(\mathrm{SD}=1.27 \mathrm{~cm})$ \\
\hline Left Hilar Height Ratio & $<0.001$ & $($ Median $=0.92)(\mathrm{IQR}=0.86-0.98)$ \\
\hline
\end{tabular}

There was a significant mean difference in the right hilar height ratio between the sex groups (Wilcoxon Ranksum Test, $p=0.017$ ) and age groups (Kruskal Wallis Test, $p=0.001$ ). The mean difference in the left hilar height ratio was not affected by sex (Wilcoxon Ranksum Test, $\mathrm{p}=0.178$ ) or age (Kruskal Wallis Test, $\mathrm{p}=0.198$ ). The right hilar and left height ratio showed a very weak correlation to height (Spearman correlation coefficient, $r=-0.10$ and $r=0.08$, respectively). The right and left hilar height ratios were not significantly different among the BMI groups (Kruskal Wallis Test, $\mathrm{p}=0.254$ and 0.20 respectively) (Table 3) (Figure 2) (Figure 3) (Figure 4). 
Table 3

The relation of the hilar height ratio with sex, age group, height and BMI of normal chest radiographs of adults at selected tertiary hospitals in Kampala.

\begin{tabular}{|c|c|c|c|c|c|}
\hline & & Right HHR & & Left HHR & \\
\hline Variable & Category & Mean & P-value & Mean & P-value \\
\hline \multirow[t]{2}{*}{ Sex* } & Male & 1.47 & 0.017 & 0.93 & 0.178 \\
\hline & Female & 1.38 & & 0.91 & \\
\hline \multirow[t]{4}{*}{ Age $\mathrm{e}^{\star \star}$} & $15-30$ years & 1.42 & 0.001 & 0.92 & 0.198 \\
\hline & $31-45$ years & 1.46 & & 0.94 & \\
\hline & $46-60$ years & 1.55 & & 0.95 & \\
\hline & $61+$ years & 1.67 & & 0.91 & \\
\hline 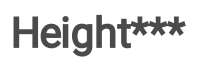 & & $(r=-0.10)$ & 0.062 & $(r=0.08)$ & 0.108 \\
\hline \multirow[t]{3}{*}{ BMI** } & Underweight & 1.30 & 0.254 & 0.86 & 0.200 \\
\hline & Normal weight & 1.45 & & 0.93 & \\
\hline & Over weight & 1.49 & & 0.94 & \\
\hline
\end{tabular}

A chest radiograph of a male and female participants with their hilar height measurements are presented in figures $5 \mathrm{~A}$ and $\mathrm{B}$.

\section{Discussion}

This study sought determine the HHR in our study population, compare it with previous studies, and to relate it with sex, stratified age groups, height and BMI. Our study had the highest values of central tendency for both the right and left hilar height ratio. The values of the right and left hilar height ratio for our study compared favourably with the original study done by Homer but with a lower level of variability (12).

The differences in hilar height ratio values in our study compared to previous studies done in Kenya (11), United states of America (USA) (12) and south Korea (13) (Table 4) could be explained by the difference in demographic characteristics, difference in sample sizes and the skewed male to female ratios. 
Table 4

The comparison of the hilar height ratio with published specific reference ranges

\begin{tabular}{|lllll|}
\hline & $\begin{array}{l}\text { Uganda, 2020 } \\
\text { (Median IQR) }\end{array}$ & $\begin{array}{l}\text { Kenya, 1995 (11) } \\
(\text { Mean } \pm \text { SD) }\end{array}$ & $\begin{array}{l}\text { Korea, 1979 (13) } \\
(\text { Mean } \pm \text { SD) }\end{array}$ & $\begin{array}{l}\text { USA, 1978 (12) } \\
\text { (Mean } \pm \text { S.D.) }\end{array}$ \\
\hline Right HHR & $1.42(1.31-1.57)$ & $1.18(0.97-1.43)$ & $1.28(1.14-1.42)$ & $1.31(1.1-1.52)$ \\
\hline Left HHR & $0.92(0.86-0.98)$ & $0.86(0.69-1.02)$ & $0.88(0.79-0.97)$ & $0.84(0.75-0.93)$ \\
\hline
\end{tabular}

The median right HHR and left HHR were 1.42 and 0.92 respectively. The mean right and left HHR in Kenyan population were 1.18 and 0.86 , respectively (11) and in Korean population were 1.28 and 0.88 respectively (13). Our study showed the highest values of central tendency for both the right and left HHR. However, the Kenyan population had the greatest variability with the lowest values of its minimum right and left HHR of 0.97 and 0.69 , respectively (11).

The median right and left HHR of this study was favorably compared with Homer's study in USA (12), where mean right and left HHR were 1.31 and 0.84 , respectively. This could be explained by the difference in sample sizes (384 versus 90 in Homer's study) and the skewed male to female ratio (85.7-14.3\% versus $45.5-54.5 \%$ in Homer's study).

Because mean was used as the measure of central tendency in the three previous studies, it is assumed that the data was normally distributed, and in normally distributed data, mean and median are equal (14); therefore, our data's median values can be compared to the means in the previous studies.

There was a significant difference $(p=0.017)$ in the median values of the right HHR between males and females at 1.47 and 1.38 respectively whereas there was no significant difference $(p=0.178)$ in the left HHR between males and females at 0.93 and 0.92 respectively. The mean right hilar height ratio between males and females in the study done by Homer (12) was 1.31 and 1.35, respectively whereas the left HHR between males and females was 0.89 and 0.82 respectively.

The mean right hilar height ratio between males and females in the Kenyan study done by Wanene (11) was 1.19 and 1.21 respectively whereas the left HHR between males and females was 0.86 and 0.84 respectively. In both the Kenyan and USA populations, females had a higher mean of the right HHR though not statistically significant. This is reversed in our study, in which females had a higher positioned right hilum compared to the males. The left hilum is, however, not affected by sex.

There was a significant mean difference $(p=0.001)$ in the right hilar height ratio among the age groups stratified into 15-year intervals. In contrast, there was no difference $(p=0.198)$ in the left hilar height ratio. There were no statistically significant differences in the different stratified age groups in the right and left hilar height ratios in the Kenyan study (11). However, the Kenyan study population was skewed to the left with only $3(1.6 \%)$ of its population aged above 45 years, which could explain the differences. In our study population, the right hilar height ratios increased with age which implies the position of the right hilum lowered with increasing age while the left hilar position remained unchanged. This could be 
explained by the fact that the left hilum is anchored by its course above the left main and upper lobe bronchus. On the other hand, vessels that constitute the right hilum course anterior to the right main bronchus and its divisions and their positions are not fixed. To the best of our knowledge, our study is the first to document the lowering of the right hilum with increasing age.

The right and left hilar height ratios were generally not affected by changes in height and weight. It is, therefore, not necessary to measure height and weight when calculating hilar height ratios.

\section{Conclusions}

The study found that the median right hilar height ratio was 1.42 and the median left hilar height ratio was 0.92 . The median left hilar height ratio is not affected by sex, age, weight and height. The right hilar height ratio varies with sex and age. The females had a higher positioned right hilum compared to the males. The position of the right hilum progressively lowers with increasing. Weight and height do not affect hilar height ratios.

\section{Abbreviations}

BMI: Body mass index.

HHR: Hilar height ratio

IQR: Interquartile range

IRB: Institutional Review Board

PA: Posterior anterior

SD: Standard deviation

SOMREC: School of Medicine Research and Ethics Committee

USA: United states of America

\section{Declarations}

\section{Ethics approval and consent to participate}

Approval to conduct the study was sought from the Department of Radiology, Makerere University. Ethical approval was sought from the Institutional Review Board (IRB) School of Medicine Research and Ethics Committee (SOMREC) (REF 2019-118). Approval and clearance from directors of the x-ray units of St. Francis Hospital Nsambya, Kawempe General Referral Hospital and Case Hospital was sought. Application for waiver of consent from SOMREC was made since the study focused on the consecutive 
collection of already acquired radiographs with no additional risk to participants included in the study. The waiver did not adversely affect the welfare or rights of participants.

\section{Consent for publication}

Not applicable

\section{Availability of data and materials}

The datasets used and/or analyzed during the current study are available from the corresponding author on reasonable request.

\section{Competing interests}

The authors declare that they have no competing interests.

\section{Funding}

No funding

\section{Authors' contribution}

All authors made a significant contribution to the study, whether that is in the conception, study design, execution, acquisition of data, analysis and interpretation, or in all these areas; took part in drafting, revising or critically reviewing the article; gave final approval of the version to be published; have agreed on the journal to which the article has been submitted; and agree to be accountable for all aspects of the work.

\section{Acknowledgements}

We acknowledge the teaching and non-teaching staff of the Department of Radiology and Radiotherapy, School of Medicine, Makerere University College of Health Sciences Makerere University, Mulago National Referral Hospital and the Radiology departmental heads at St. Francis Hospital Nsambya, Kawempe General Referral Hospital and Case Hospital for their active support and help accorded in this study.

\section{References}

1. Vano E. ICRP recommendations on 'Managing patient dose in digital radiology'. Radiation protection dosimetry. 2005;114(1-3):126-30.

2. Winkler MH, Touw HR, van de Ven PM, Twisk J, Tuinman PR. Diagnostic accuracy of chest radiograph, and when concomitantly studied lung ultrasound, in critically ill patients with respiratory symptoms: a systematic review and meta-analysis. Critical care medicine. 2018;46(7):e707-e14. 
3. Espinosa JA, Nolan TW. Reducing errors made by emergency physicians in interpreting radiographs: longitudinal study. BMJ. 2000;320(7237):737-40.

4. Al Aseri Z. Accuracy of chest radiograph interpretation by emergency physicians. Emergency Radiology. 2009;16:111-4.

5. Donald JJ, Barnard SA. Common patterns in 558 diagnostic radiology errors. Journal of medical imaging and radiation oncology. 2012;56(2):173-8.

6. Ropp A, Waite S, Reede D, Patel J. Did I miss that: subtle and commonly missed findings on chest radiographs. Current problems in diagnostic radiology. 2015;44(3):277-89.

7. Nazerian P, Volpicelli G, Vanni S, Gigli C, Betti L, Bartolucci M, et al. Accuracy of lung ultrasound for the diagnosis of consolidations when compared to chest computed tomography. The American journal of emergency medicine. 2015;33(5):620-5.

8. Boyars M. Chest Roentgenography for Pulmonary Evaluation. Clinical Methods: The History, Physical, and Laboratory Examinations 3rd edition: Butterworths; 1990.

9. Robbins LL, Hale $\mathrm{CH}$. The roentgen appearance of lobar and segmental collapse of the lung: $A$ preliminary report. Radiology. 1945;44(2):107-14.

10. Lubert M, Krause GR. Patterns of lobar collapse as observed radiographically. Radiology. 1951;56(2):165-82.

11. Wanene GL. The normal hilar height ratio in Kenyan Africans; a study at Kenyatta National Hospital, Nairobi: University of Nairobi; 1995.

12. Homer MJ. The hilar height ratio. Radiology. 1978;129(1):11-6.

13. Yoo KH, Lee NJ, Seol HY, Chung KB. Hilar height ratio in normal Korean. Journal of the Korean Radiological Society. 1979;15(2):373-5.

14. Mishra P, Pandey CM, Singh U, Gupta A, Sahu C, Keshri A. Descriptive Statistics and Normality Tests for Statistical Data. Ann Card Anaesth. 2019;22(1):67-72.

\section{Figures}



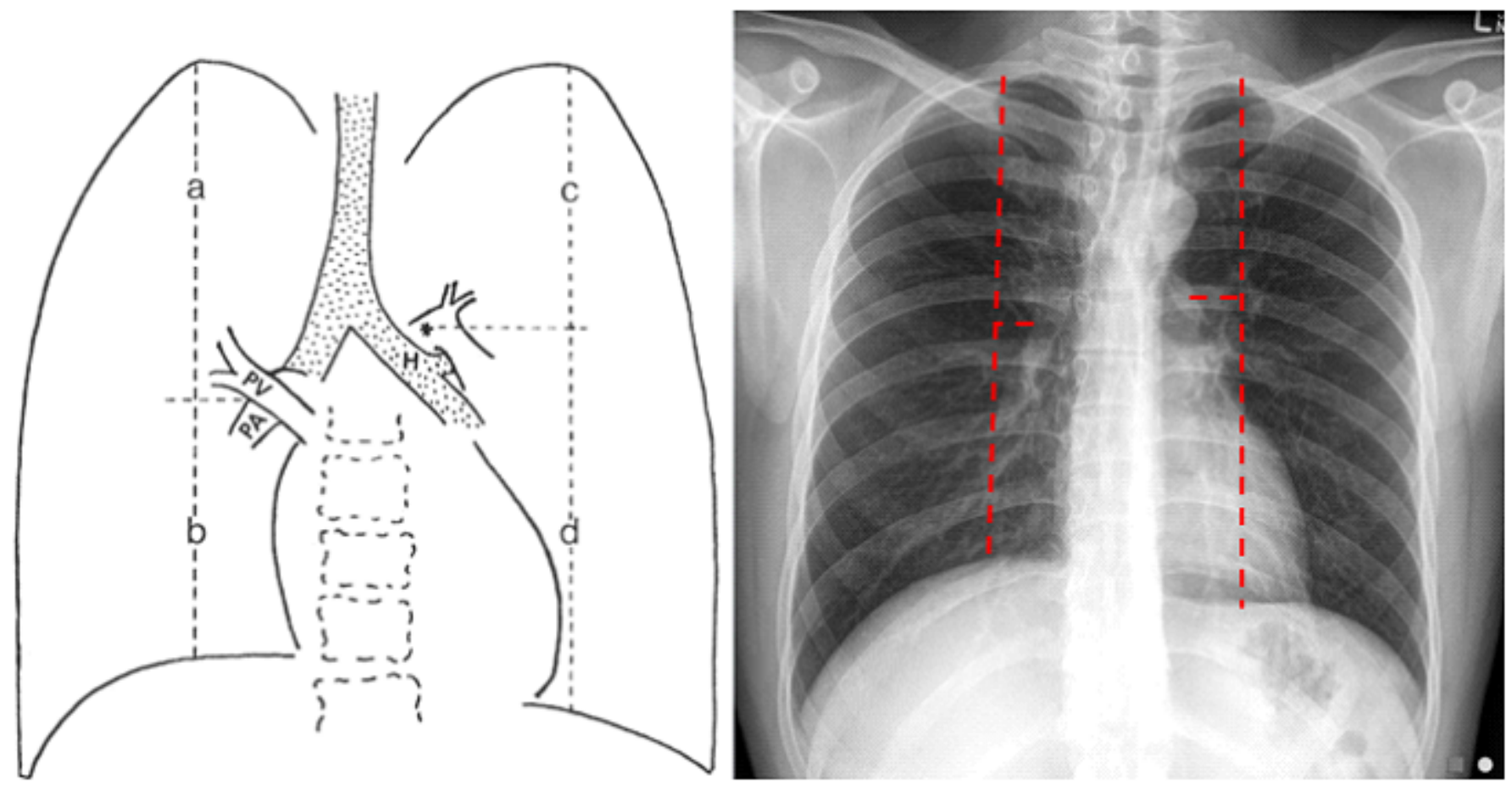

\section{Figure 1}

Diagrammatic illustration of the hilar height ratio (HHR)calculation (13)(left) and the corresponding normal plain radiograph (right). a: distance from right hilum to the lung apex, b: distance from right hilum to the diaphragm, c: distance from left hilum to the lung apex, $d$ : distance from left hilum to the diaphragm. Calculation of HHR Right HHR $=a / b$ Left HHR $=c / d$ 

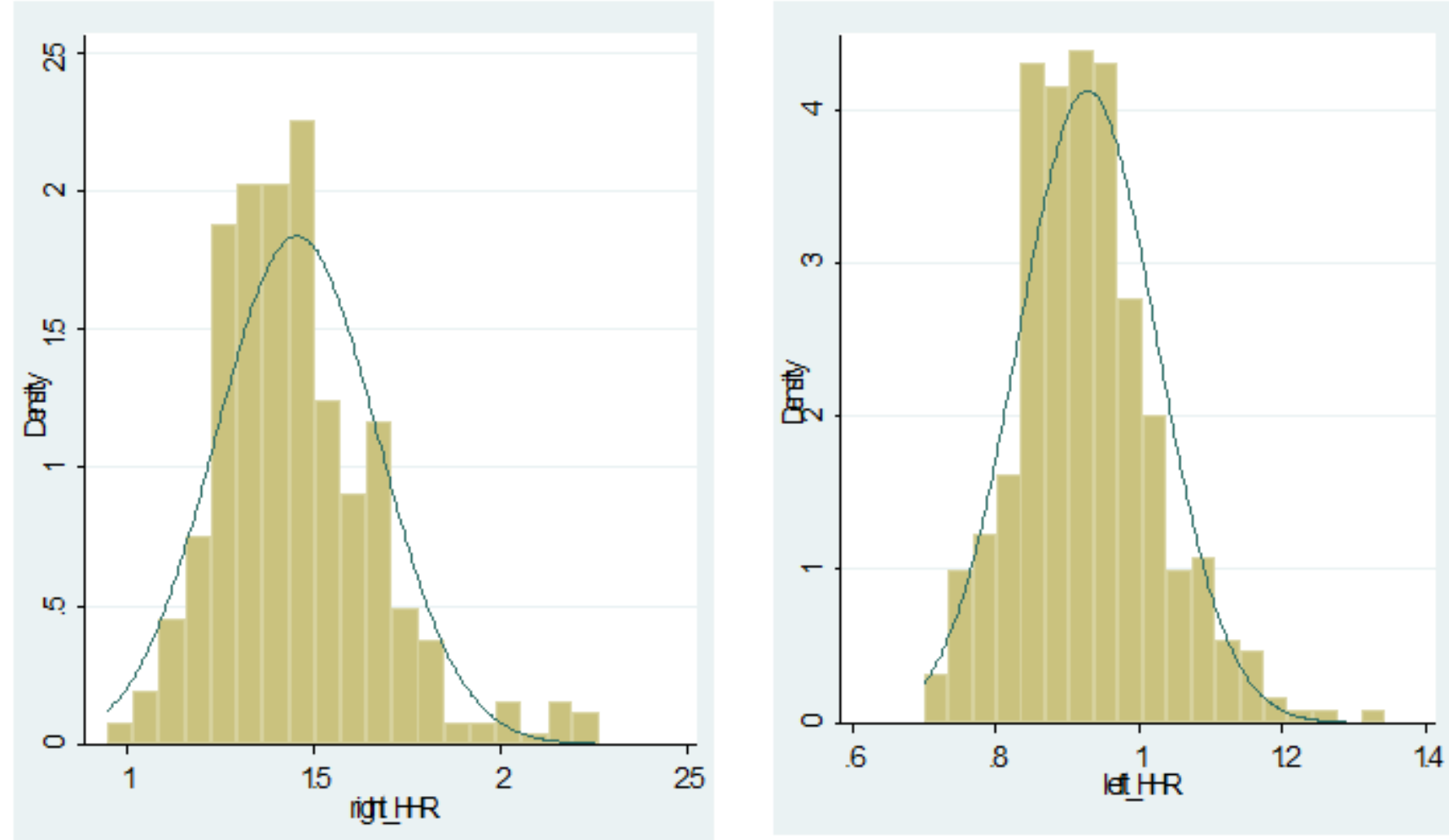

\section{Figure 2}

Histogram showing the distribution of hilar height ratios

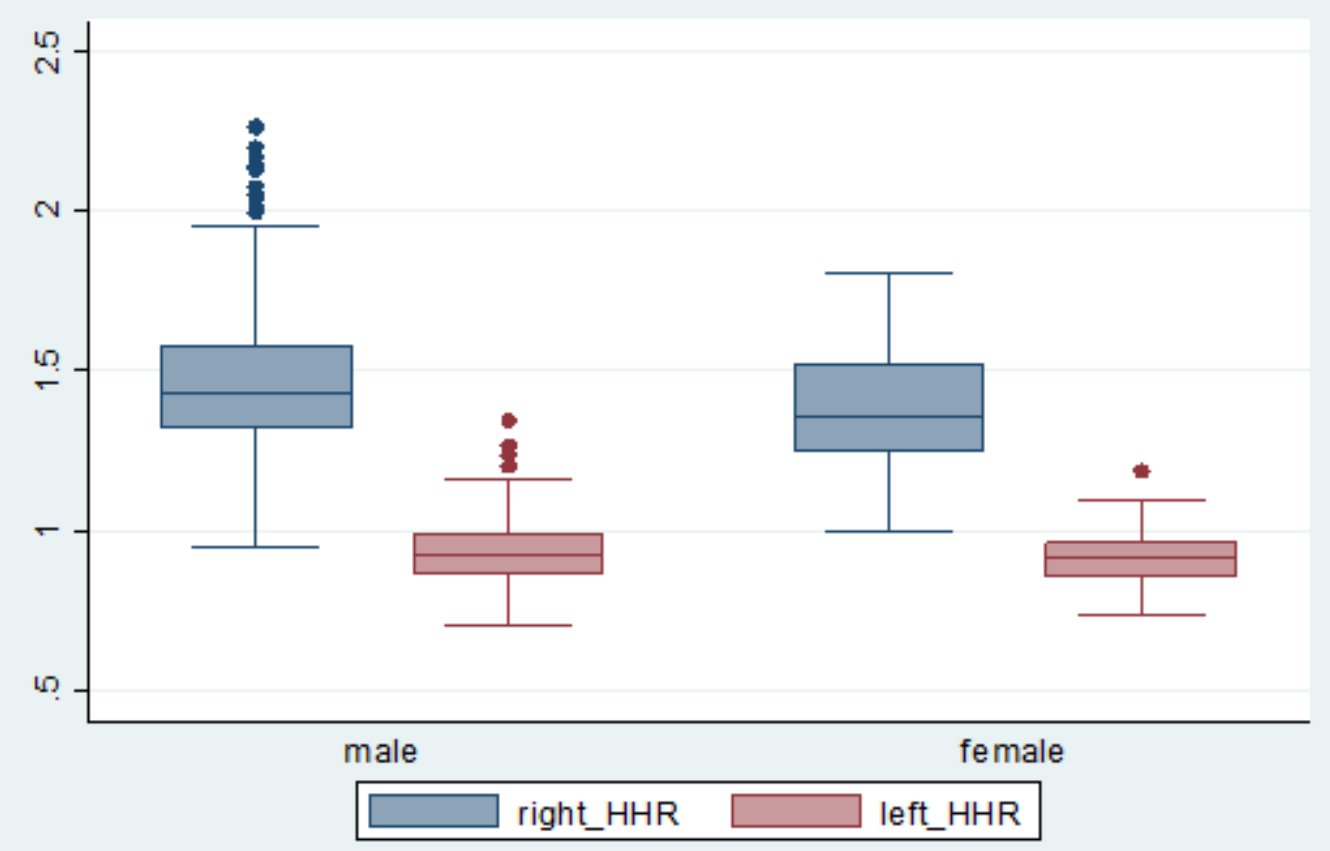

Figure 3 
Box and whisker plots of hilar height ratios against the gender of participants
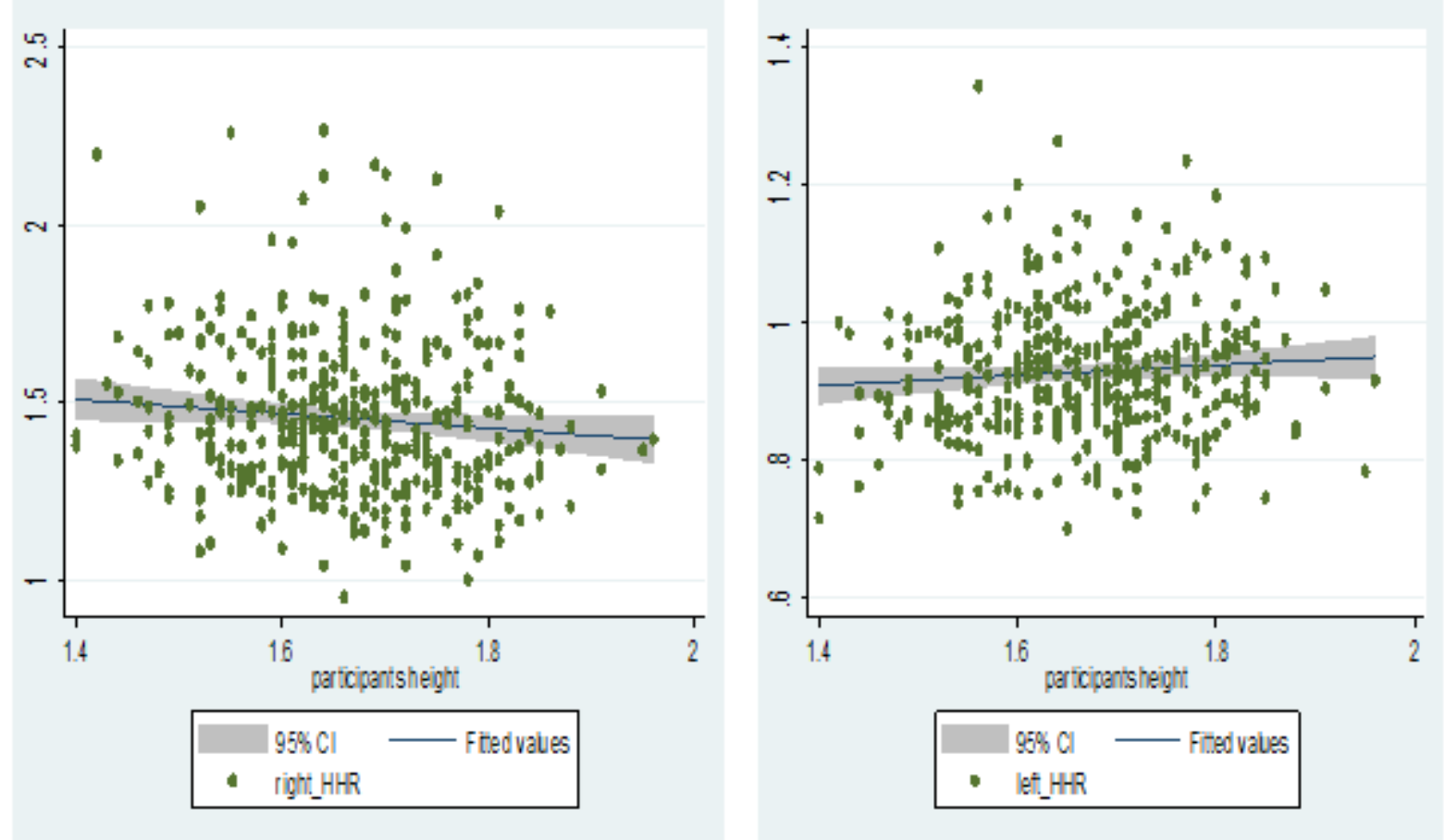

\section{Figure 4}

correlation between hilar height ratio and height of participants

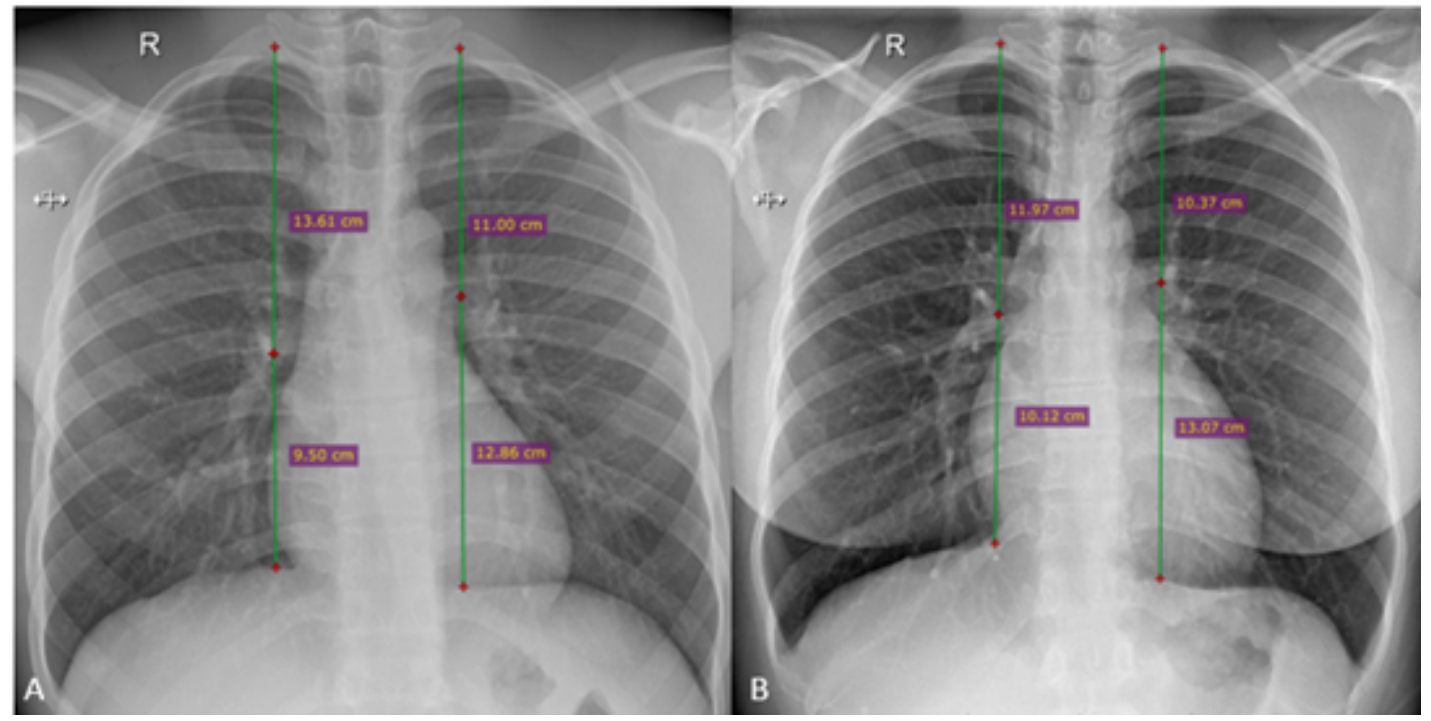

\section{Figure 5}

A; PA chest radiograph of a 23-year-old male $1.64 \mathrm{~m}$ in height, $B M l$ of $24.84 \mathrm{~kg} / \mathrm{m} 2, a=13.61 \mathrm{~cm}, b=9.5 \mathrm{~cm}$, $\mathrm{C}=11.0 \mathrm{~cm}, \mathrm{~d}=12.86 \mathrm{~cm}, \mathrm{RHHR}=1.43$ and $\mathrm{LHHR}=0.86$. Figure $5 \mathrm{~B} ; 50$-year-old male $1.75 \mathrm{~m}$ in height, $\mathrm{BMI}$ of $22.24 \mathrm{~kg} / \mathrm{m} 2, a=15.50 \mathrm{~cm}, \mathrm{~b}=8.78 \mathrm{~cm}, \mathrm{c}=12.70 \mathrm{~cm}, \mathrm{~d}=13.98 \mathrm{~cm}, \mathrm{RHHR}=1.77$ and $\mathrm{LHHR}=0.91$

\section{Supplementary Files}


This is a list of supplementary files associated with this preprint. Click to download.

- APPENDIXI.docx 